\title{
Emek Değer Teorisi ve Fayda Değer Teorisinin Karşılaştırılmalı Analizi
}

\author{
TuĞBA KOYUnCU (10 ${ }^{1}$
}

Başvuru: 21.05.2020; Düzenlenme: 29.05.2020; Kabul: 01.06.2020

\begin{abstract}
Değer konusu ve değerin kaynağının ne olduğu uzun zamandır iktisatçıların ve düşünürlerin araştırma konusu olmuştur. Adam Smith, David Ricardo ve Karl Marx bir malın kullanım değerini dikkate almamışlardır. Onlar daha çok bir malın değişim değerini dikkate alarak o malın değişim değerini üretiminde harcanan emek zamanı miktarının belirlediğini düß̧̈̈mmüslerdir. Bu iktisatçılar emek değer teorisine farklı bakıs açıları ile yaklaşmıs olmalarına rağmen değerin kaynağının emek olduğu konusunda ortak bir kanıya varmışlardır. Değer teorisine katkı sağlayan bir diğer akım ise W. Stanley Jevons, Leon Walras, Carl Menger ve Alfred Marshall'ın öncülük ettiği bir malın değerini o malın sahip olduğu fayda miktarının belirlediği fayda değer teorisidir. Bu çalı̧̧mada emek değer ve fayda değer teorileri karşılaştırılarak günümüzdeki geçerlilikleri tartışılmıştır. Ekonomik sistemin içinde birçok değişken tarafından etkilenen değerin böylesine karmaşık bir yapının içinde sadece emek veya sadece fayda tarafından belirlenebileceği sonucuna varılamayacağ d düşünülmektedir. Ayrıca emek ve faydanın dışında bir malın değerini etkileyen çok sayıda değişken olduğu sonucuna varılmıştır.
\end{abstract}

JEL kodlart: B10, B12, B13

Anahtar kelimeler: Değer Kavramı, Emek Değer Teorisi, Fayda Değer Teorisi

\section{Giriş}

Değerin kaynağının ne olduğu uzun yıllar birçok iktisatçı ve düşünür tarafından tartışılan bir konu olmuştur. Mallar arasındaki değişimin hangi kriterlere göre belirleneceği ve bölüşümün sermaye ve emek gibi üretim faktörleri arasında nasıl dağıtılacağı düşünülmüştür. $\mathrm{Bu}$ nedenle değerinin bir malın üretiminde kullanılan emek tarafından mı belirlendiği yoksa o mal zaten faydalı olduğu için mi insanların onu

1 İktisat ABD Programı, Sosyal Bilimler Enstitüsü, Eskişehir Osmangazi Üniversitesi, Türkiye. (e-mail: tugbakoyuncu9106@gmail.com)

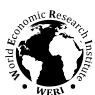

üretmek için emek harcadığ 1 veya bir malın maliyet unsurlarındaki değişimin mi değerini etkilediği gibi düşünceler kapsamında çeşitli teoriler üretilmiştir.

Adam Smith zamanı ikiye ayırarak sermaye birikiminin ve özel mülkiyetin olduğu zamanlarda ve sermaye birikiminin ve özel mülkiyetin olmadığg zamanlarda değerin belirleyicisinin ne olduğunu açılklamıştır. Arza dayalı olan bu modele göre sermaye birikiminin ve özel mülkiyetin olmadığ 1 zamanlarda bir malın üretimi için kullanılan emek zamanı miktarı o malın değerini belirlerken sermaye birikiminin olduğu zamanlarda emeğin yanında sermaye ve toprak gibi diğer üretim faktörlerinin de yer aldı̆̆ 1 
düşünülmüştür. David Ricardo ve Karl Marx bu teoriyi benimseyerek tüm zamanlarda değerin emek tarafindan belirlendiğini, doğrudan ve dolaylı emek ayrımı yaparak sermayenin içerisinde de dolayl bir emek bulunduğunu savunmuşlardır. Marx emeğin artık değer oluşturduğunu ve kapitalistler tarafindan sömürüldüğünü düşünmüştür. Faydacı yaklaşımlara göre ise bir malın kullanım değeri yani faydası bir malın değişim değerini belirlemektedir. Fayda değer teorisini benimseyen iktisatçılar malların değişim oranlarının marjinal faydaları oranına eşit olduğu tespitinde bulunmuşlardır.

Peki gerçekten de bir malın değerini belirleyen şey nedir? Üretimi için kullanılan emek zamanı miktarı mı yoksa içerdiği fayda miktarı mı? Bu çalışmada emek değer ve fayda değer teorileri karşlaştırılarak değerin kaynağın ne olduğu sorusunun cevabı aranmıştır. Konunun öneminin ve amacının anlatıldığı bu bölümün ardından ikinci bölümde değer kavramı ve Klasik İktisat öncesi bazı iktisadi düşünürlerin değer konusundaki fikirlerine değinilmiştir. Üçüncü bölümde "emek değer teorisi" Adam Smith, David Ricardo ve Karl Marx açısından incelenirken dördüncü bölümde "fayda değer teorisi" kapsamında W. Stanley Jevons, Carl Menger, Alfred Marshall ve Leon Walras' in düşüncelerine yer verilmiştir. Değer üzerine Thomas Aquinas, Aristo, John Locke, Jean Bodin, William Petty, J. Maynard Keynes, J. A. Schumpeter, A. C. Pigou, Alvin Hansen, F. V. Wieser, Böhm-Bawerk gibi bir çok düşünür katkı sağlamıştır. Ancak konunun amacından sapmamak için daha çok emek değer ve fayda değer teorisinin özü aktarılmıştır. Son bölümde ise bu iki teori karşılaştırılarak geçerliliği tartışılmıştır.

\section{Değer Kavramı Üzerine}

Değer kavramının kökeni Latince " $v a$ lere" kelimesine dayanmaktadır. Türk Dil Kurumu sözlüğünde ise değer kavramı " bir şeyin önemini belirlemeye yarayan soyut ölçü, parayla ölçülebilen karşılık, yüksek ve yararlı nitelik" olarak tanımlanmaktadır (I. Aydın ve Yılmaz, 2014). Bir diğer kaynakta değer "bir kişi ya da firmanın strateji belirleme unsurlarmdan biri" olarak ifade edilmektedir (Demir, 2016). Değer kavramı ekonomi, psikoloji, felsefe, sosyoloji gibi birçok bilim dalı ile yakın ilişki içindedir. Psikolojide değerin insan davranışlarında belirleyici rol aldı̆̆ ve tüm nesnelerin bir değeri olduğundan bahsedilmektedir (Güngör, 1993). Felsefe açısından ise değer öznel, nesnel ve göreceli olarak ayrıma tabi tutulmaktadır. Değere söz konusu olan nesnenin yararlı, kullanışlı, iyi mantıksal açıdan doğru veya yanlış olması felsefi açıdan sorgulanmaktadır. Ekonomik açıdan değerin tanımı ve ölçümü uzun yıllardır birçok iktisatçı ve düşünürün ilgi alanı olmuştur. Genel olarak değer, bir malın faydası ile maliyetlerinin birbirine oranı olarak tanımlanmaktadır (DeSarbo vd., 2001). Ancak düşünürler değer oluşumunun kaynağını irdeleyerek, fayda, maliyet, emek, arz ve talep açısından farklı tanımlamalar yapmışlardır. Bu durum değerin "objektif" ve "subjektif" bakış açısı ile çok sayıda tanımlamaya yol açarak "değer problematiğine" yol açmıştır.

Değer problematiğinin incelenmesi Orta Çă̆ düşünürleri Eflatun ve Aristo'ya kadar dayanmaktadır. Değerin kaynağının ne olduğunu inceleyen Aristo (M.Ö. 384-322) birkaç temel unsuru göz önünde bulundurarak değeri açıklamıştır. O, bir malın değerini, o malın sahibine sağladığı yararın yanında söz konusu malın kullanım değerinin de belirlediğini düşünmüş̧tür. Ayrıca kullanım sırasına bağlı olarak malın talebinin değişebileceğini ifade etmiştir. Aristo'nun şüphesiz değer teorisine en büyük katkısı kıtlı unsuru tarafından etkilendiğini varsaydığı değişim değeridir (Küçükkalay, 2017). Ona göre mal veya hizmetlerin değişiminin mümkün olabilmesi için değişime söz konusu olan şeylerin değerlerinin eşit olması gerekmektedir. O bu görüşünü "Eşitlik olmadan değişim, ortak 
bir ölçü ile ölçülebilirlik olmadan da eşitlik olamaz" ifadesi ile belirtmiştir. Aristo bu düşünceleri ile iktisadi düşüncenin temelini oluşturan kullanım değeri ve değişim değeri ayırımını oluşturmuştur. Her ne kadar bu ayrımı yapmıs olsa da bu konuda bir teori geliştirememiştir. Ancak bugün iktisat literatüründe yaygın olarak bildiğimiz iki zıt görüş olan, kullanım değerinden yani bir malın faydasından hareketle değişim değerine ulaşan "emek değer teorisi" ve bir malın değişiminin mümkün olması için mutlaka kullanım değerinin olması gerektiğini savunan "fayda değer teorisi" gibi iki karşıt teorinin temelini oluşturmuştur (Selik, 1980).

Merkantilistler bir malın değerinin nereden kaynaklandığını sorgulamak yerine fiyat artış ve azalışlarının nedenini araştırmışlardır. Orta Çă̆ iktisadi görüşünün kabul ettiği faydanın değerin belirleyicisi olduğu subjektif değer teorisini sürdürmüşlerdir. Ancak William Petty (1623-1687) değerin belirlenmesinde subjektif görüşten ziyade objektif bir görüş sergilemiştir. Petty, malların değişim değerlerini ve emeğin değerini bir malın üretimi için harcanan emek zamanı ile ilişkilendirmiştir. Ayrıca değişim değerini belirlemede emeğin yanında arz ve talep arasındaki ilişkilerin, satıcılar arasındaki rekabet durumunun ve geleneklerin de etkili olduğunu düşünmüştür (Gözen, 2019). Bu nedenle dış ticaret üzerindeki engellerin kaldırılmasının gerektiğini düşünerek bir malın değerini o malın üretimi için harcanan emeği aşan kısım olarak nitelendirmiştir. Petty bu düşünceleri ile Klasik Emek Değer Teorisi'nin yapı taşlarını oluşturmuştur (Adaçay, 2017). John Locke (1632-1704), değerin arz ve talep koşulları tarafindan belirlendiğini düşünmüş bunu "herhangi bir malın fiyatı alıcı ve satıcıların sayısına göre düşebilir veya yükselebilir" şeklinde ifade etmiştir. Talebin belirlenmesinde subjektif faktörlerin yanında bir malın değerinin malın miktarıyla da ilişkili olduğunu savunmuştur (Savaş, 2000). Locke'a göre değerin esas kaynağı emektir ve emek malların değerini birbirinden ayıran bir unsurdur (Sewall, 1901).

Nicholas Barbon (1640-1698), değerin arz ve talep tarafından belirlendiğini düşünmüştür. Barbon'a göre bu değer piyasa fiyatı olarak nitelendirilmiştir. Bir malın arzının değişmesinin piyasa fiyatını etkilemenin yanında bu fiyatın oluşabilmesi için söz konusu malın kullanım değerinin olması gerektiğini vurgulamıştır (Ertuğrul, 2014). Barbon'nun bu düşünceleri bir malın kullanım değeri olmadığında piyasa fiyatının da oluşmayacağını göstermektedir. Ona göre kullanım değeri yani fayda fiyatın oluşumunda temel etkendir. Ferdinando Galiani'ye göre (1728-1787) malların kit olup olmama durumu ve bu malların sağladığ fayda mallar arasındaki oransal değeri ifade etmektedir. Galiani "toplam fayda" ve "marjinal fayda" ayrımını yapmamıs olsa da faydanın iki mal arasındaki oransal değeri temsil ettiğini düşünerek daha sonra Karl Menger (1840-1921), William Stanley Jevons (1835-1882) ve Leon Walras (1834-1910) gibi iktisatçlların düşüncelerine öncülük etmiştir (Kauder, 2015).

İbn-i Haldun'a göre (1332-1406), üretimin gerçekleşme sürecinde elde edilen malların tek kaynağı emektir. Haldun, üretim sürecinde kullanılan alet ve araçlarm Allah tarafindan hazır verilmediğini ve bunların da yine insan emeği ile üretildiğini ifade etmiştir. Ona göre insanlar yalnızca emek harcayarak kazanç săglayabilmektedir (Küçükkalay, 2019). Bir malın üretiminde mutlaka emeğin bulunması durumu, Haldun'u o malın değerinin harcanan emek tarafindan belirlendiğine götürmüştür. Ona göre emek alıcısı bulunan satılmak, üzere pazara götürülen mal ve eşya gibidir (Haldun, 2018). Haldun, değerin asıl kaynağının emek olduğunu ve malların fiyatları ile faydası arasında bir ilişki olduğunu savunmuştur. Onun bu düşünceleri değerin objektif olduğunu ve bunun yanında faydanın da göz ardı edilmediğini göstermektedir (Erdem, 2017). Emek kullanılarak üretilen mal veya hizmetlerden elde edilen kazanç sermaye 
sahibi için artı değer oluşturmaktadır. Ancak Haldun bu artı değerin toplumsal refah ve kalkınmayı artırıcı bir unsur olduğunu ifade etmiştir (Çöpoğlu ve Kuran, 2019).

\section{Emek Değer Teorisi}

\subsection{Adam Smith'in Emek Değer Te- orisi}

Adam Smith (1723-1790) bir maln değerinin kaynağında emek faktörünün mutlak olduğunu düşünmüştür. Smith bir malın değişim (mübadele) değeriyle kullanım değeri arasında ayrımı kabul etmiştir ancak teorisinde kullanım değerini göz ardı etmiştir. $\mathrm{O}$, emek ürünlerinin insanlarm gereksinimlerini karşılayarak faydalı olmasını bir malın kullanım değeri olarak nitelendirirken, bir malın diğer mallara oranını değişim değeri olarak ifade etmiştir (Kazgan, 2006). Ona göre doğada bol bulunan su ve hava gibi bazı malların kullanım değeri büyük iken, bu tür malların değişim değeri bulunmamaktadır. Ancak kullanım değeri bulunmayan mallarm (elmas gibi) değişim değeri büyüktür (Bocutoğlu, 2012b). Smith'in kullanım değerini dikkate almaması daha sonra fayda değer savunucuları tarafından ifade edilen "elmas-su paradoksu" olarak bilinen hataya yol açmıştır.

Hunt (2009) Smith'in emek değer teorisini şöyle ifade etmiştir: "Bir malın değişim değeri o malın içerdiği emek miktarı artı mal üretiminde kullanılan üretim araçlarını üreten dolaylı emeğin ve mal üretiminde kullanılan üretim araçlarını kullanan doğrudan emeğin üretimde kullanıldı ğı zaman belirlenmektedir." Smith bu emeği üretken (verimli) ve üretken olmayan (verimsiz) emek olmak üzere ikiye ayırmıştır. Üretken emek bir mala artı değer katmaktadır. Üretken olmayan emek ise mevcut malın yeni bir değer oluşturmadan biçimin değiştirilmesi durumudur (Ertuğrul, 2014). Smith'e göre ormancının, çiftçinin emeği üretken emek iken, marangozun ağacı biçimlendirip masa haline getirmesi veya firmcinın ekmek yapması üretken emek değildir. Bu nedenle
Smith hizmet sektörünün üretken olmadığını düşünmüştür (İşler, 2018).

Smith'e göre ekonomide verimlilik, iş bölümü ve uzmanlaşma ile artmaktadır. İş bölümü ve uzmanlaşma ise değişimi zorunlu hale getirmektedir. Ona göre ekonomi sermaye birikiminin olmadığı ve sermaye birikiminin olduğu iki ayrı döneme ayrılır. Sermaye birikiminin olmadığ dönemlerde bir malın değeri, ona harcanan emek zamanının değişime girmesi ile belirlenmektedir. Örneğin 1 kunduz 1 günde ve 1 geyik 2 günde avlanıyorsa, 1 geyik için harcanan emek zamanı miktarı ve 2 kunduz için harcanan emek zamanı miktarı eşit olmaktadır. Bu durumda 1 geyik ile 2 kunduzun değeri birbirine eşit olmaktadır. Ancak toprakların özel mülkiyete geçerek, sermaye birikiminin başladığı sanayi toplumlarında üretim için emeğin yanında sermaye ve toprak girdileri de kullanılmaktadır. Be nedenle sermaye birikiminin olduğu sanayi toplumlarında bir malın değerini emeğin yanında sermaye ve toprak da belirlemektedir (Küçükkalay, 2019).

Smith emek değer teorisinde, sermaye, emek ve toprak gibi üretim faktörlerinin bir malın değerini belirleyeceğini savunmuştur. Ona göre mal ve hizmetlerin alınıp satıldığı piyasa fiyatı ile doğal fiyat arasında fark vardır. Piyasa fiyatı arz ve talep tarafından piyasada ortaya çıkan fiili fiyatı ifade ederken, doğal fiyat ise üretim maliyetlerini ifade eden ücret, rant ve karm toplamindan oluşmaktadır (Hunt, 2009). Smith doğal fiyatm üretim maliyetleri tarafindan belirlenen denge fiyatı olduğunu düşünmüştür. Kısaca Smith'in emek değer teorisinde bir malın değeri açısından mübadele değeri dikkate alınmış ve sanayileşmiş sermaye birikiminin olduğu ülkelerde bu değer harcanan emek zamanı miktarının yanında sermaye ve toprak gibi üretimin gerçekleşmesinde etkili olan maliyet unsurları tarafindan da belirlenmektedir. 


\subsection{David Ricardo'nun Emek Değer Teorisi}

David Ricardo (1772-1823) Smith gibi bir malın kullanım ve değişim değeri ayrımını benimsemiştir. Ancak kullanım değeri üzerinde fazla durmamıştır. Onun asıl amacı sermaye, toprak ve emek sahiplerinin üretimden alacağı payları belirlemek olmuştur. Ricardo, rantlarm üretim maliyetleri içinde yer almadığını ve bu nedenle bir malın değerinin belirleyicisi olamayacağını düşünmüştür. Dolayısıyla Ricardo'nun emek değer teorisine göre malların değeri Smith'ten farklı olarak ücret ve karların üretim maliyetlerine oranı şeklinde belirlenmektedir (Niehans, 1994). Ricardo'ya göre malların kıtlığ veya bolluğu değişim değeri üzerinde etkilidir.

Ricardo, Smith'in kunduz ve geyik örneğini desteklemiştir ancak bazı durumlarda bir mala harcanan emek zamanı miktarının o malın değişim değerini belirlemekte yetersiz olduğunu düşünmüştür. $\mathrm{O}$, malların faydalı olmaması durumunda piyasada bir değerinin oluşmayacağını düşünerek, bir malın kıtlık veya bolluğunun değişim değeri üzerindeki etkisini şu ifadelerle belirtmiştir: "Mallar faydalı olarak mübadele edilebilir değerini iki kaynaktan alırlar: az bulunur olmalarından ve onları elde etmek için gerekli emek miktarından." Bu nedenle bir malın değerini emeğin yanında o malın kitlık ve bolluğunun da etkilediğini düşünmüştür. Dolayısıyla Ricardo malları "çoğaltılabilen" ve "çoğaltılamayan" olmak üzere ikiye ayırmıştır. Ona göre tekrar yapılması mümkün olmayan heykeller, klasik tablolar ve eserler gibi çoğaltılamayan mallar üretimi için harcanan emek zamanı miktarı ile değerlendirilmemektedir (Ricardo, 1891). Yani bu tür malların değeri onların üretimi için harcanan emek zamanı miktarından bağımsız olarak belirlenmektedir. Ricardo bu durumu, bu tür malların kit olmasindan kaynaklandığını ve bu malları talep eden kişilerin zenginliklerinden kaynaklandığını düşünmüştür (Doğruyol ve Aydınlar, 2015). Ricardo'ya göre üretim tekniğinde emek "dolaylı" ve "dolaysız" olmak üzere iki ayrı formda bulunmaktadır. Dolaylı emek bir malın üretiminde kullanılan mal veya üretim araçlarının içerdiği emek zamanını temsil ederken dolaysiz emek bir malın üretiminde sadece üretim araçlarının kullanılarak harcanan emek zamanını ifade etmektedir. Dolaylı ve dolaysiz emek toplamı ise toplam emek miktarını vermektedir. Örneğin dolaysız emekte, bir kilogram buğday üretimi için sadece $x$ birim kadar emek kullanıldığında bir kilogram buğdayın fiyatı $x$ olur. Dolaylı emek kullanımında ise bir kilogram buğday üretiminde $x$ birim kadar emek ve $a$ birim kadar da buğday kullanıldığında bir kilogram buğdayın fiyatı $x$ ve $a^{\prime}$ nın içerdiği toplam emek zamanı miktarı kadardır. Bu tekniğe göre verimli üretim gerçekleştirebilmek için üretim tekniğinde kullanılan $a$ birim buğday miktarı bir kilogramdan küçük olmalıdır. Yani bir kilogram buğday için kullanılan tohum miktarı bir kilogramdan daha az olmalıdır. (Akyüz, 2009). Ancak Ricardo bu durumun gerçekleşmesi için bütün malların üretimi için aynı nitelikte emek yani emeğin homojen olduğunu ve ölçeğe göre verimin sabit olduğunu varsayımını yapmıştır.

Ricardo malların üretiminde dolaylı ve dolaysız olmak üzere sadece emek faktörünün bulunduğunu savunmaktadır. Mallar arasında değişim oranının ise toplam emek faktörleri oranına eşit olduğunu ifade etmiş̧ir: "Bir malın değerini o malı üretmek için emeğe ödenen miktarın azlığı veya çokluğu değil o malın üretiminde kullanılan emeğin nispi fiyatı belirler." (Sraffa, 1951). Ricardo'nun bu düsüncesi sayısal olarak şöyle ifade edilmiştir: bir $A$ malı üretiminin sadece dolaysız emek kullanılarak gerçekleştirildiği durumda, $x_{a}$ birim kadar emek kullanıldığında ve emeğin bir biriminin maliyeti $w_{a}$ olduğunda bir birim $A$ malı üretiminin maliyeti $x_{a} w_{a}$ olmaktadır. Yine sadece dolaysız emek kullanılarak bir B malı üretimi için $x_{b}$ birim kadar emek ve $w_{b}$ kadar bir birim emeğin maliyeti olduğunda B malı üretiminin maliyeti $x_{b} w_{b}$ olacaktır. $A$ ve $B$ malının birbiri ile değişim oranı şu 
şekilde olacaktır (Ertuğrul, 2014):

$$
\frac{P_{a}}{P_{b}}=\frac{x_{a} w_{a}}{x_{b} w_{b}}
$$

Geçimlik ücret düzeyinin $\left(w_{s}\right)$ emek maliyetlerine eşit olduğu durumda ise bu eşitlik (1) şöyle olacaktır:

$$
\frac{P_{a}}{P_{b}}=\frac{x_{a} w_{a}}{x_{b} w_{b}}=\frac{x_{a} w_{s}}{x_{b} w_{s}}=\frac{x_{a}}{x_{b}}
$$

Eşitlik (2)'de açık bir şekilde ifade edildiği gibi $A$ ve $B$ mallarmın değişim değerleri oranı bu malların üretimi için gerekli emek miktarı zamanı tarafindan belirlenmektedir. Ricardo'nun emek değer teorisinde üretim maliyeti yaklaşımı ile bir malın değerinin yalnızca emek olduğu açıkça görülmektedir. Arz yönlü bir yaklaşımı benimseyerek, bir malın değişim değerini objektif değer teorisi ile açıklamıştır. Ancak Ricardo'nun emek değer teorisi, emeğin homojen olmadığ 1 , nitelikli ve niteliksiz işçilerin emek verimliliğinin farklı olması ve sermayenin üretime katılması ile eleştirilmiştir (Akyüz, 1980).

\subsection{Karl Marx'ın Emek Değer Teorisi}

Karl Marx (1818-1883) değer yaklaşımının temeli Ricardo'nun emek değer teorisine dayanmaktadır. Ancak Marx'in emek değer teorisi Ricardo'nun emek değer teorisinden farklıydı. Ricardo'ya göre bir malın üretimi için harcanan emek zamanı bu malın nispi değerinin ölçüsü iken Marx'a göre bir malın üretimi için harcanan emek zamanı bu malın mutlak değerini temsil etmektedir. Yani Marx'ın emek değer teorisinde bir malın değerinin tek ve mutlak belirleyicisi emektir, sermaye ve toprağın bu malın değerinde herhangi bir etkisi yoktur (Bocutoğlu, 2012a).

Marx bir malın hem kullanım hem de değişim değeri olabileceğini ve değişim değerinin kullanım değerinden bağımsız olduğunu düşünmüştür (Desai, 2009). Marx kullanım değerini sadece insan ve meta arasında ilişki olarak tanımlamış ve bir malın değerinin oluşumu açısından incelememiştir. $\mathrm{Bu}$ onun şu ifadelerinde açıkça belirtilmektedir: "Metalar, kullanım değerleri ya da demir, keten bezi, buğday vb. gibi meta cisimleri biçiminde dünyaya gelir. $\mathrm{Bu}$ onların basit fiziksel biçimidir. Buna karşın yalnızca iki yönlü oldukları, ayn anda hem kullanim nesneleri hem de değer taşıyıcıları oldukları için metadırlar. $\mathrm{Bu}$ yüzden, bunlar ancak ikili biçimde, yani fiziksel biçimde ve değer biçiminde oldukları sürece meta olarak görünürler ya da meta biçimine sahip bulunurlar" (Marx, 2011). Ona göre kullanım değeri bir malın veya metanın fiziksel bir biçimidir ve değişim değerini etkilemez. Örneğin bir $X$ malı 4 saat emek harcanarak bir $Y$ malı ise 12 saat emek harcanarak üretiliyorsa $X$ ve $Y$ mallarının fiziksel biçimi veya faydasından bağımsız olarak bu malların değişim değeri emek tarafindan belirlenmektedir. $\mathrm{Bu}$ malların göreceli değişim değeri $3 X=Y$ olacaktır.

Marx, değer ve para birimi arasındaki ilişkiyi şu ifadelerle açıklamıştır: "Para kristali, farklı türden emek ürünlerinin fiilen birbirlerine eşitlenmelerine ve dolayısıyla fiilen metalara dönüştürülmesine aracılık eden mübadele sürecinin zorunlu bir ürünüdür" (Marx, 2011). Marx'm bu ifadesini bir önceki göreceli değişim değeri örneğimize uyguladığımızda $X$ malının 4 birimi, $Y$ malını 1 birimi ve $Z$ malının 2 biriminin değeri $12 \mathrm{TL}$ ise bu malların bir biriminin değişim değeri sırasıyla 3 TL, 12 TL, 6 TL' dir. Bu durumda $4 X=Y=2 Z$ değerine eşit olacaktır. Ayrıca Marx nitelikli ve niteliksiz emek ayrımını ortadan kaldırarak, tüm emeğin üretken olduğunu düşünmüştür (Koç, 2014). O tamamının üretken olduğunu düşündüğü emeği, "gerekli sosyal emek" olarak isimlendirmiştir. Örneğin nitelikli bir işçinin bir işi 4 saatte, normal bir iş̧̧inin 6 saatte bitirdiği varsayıldığında bu iş sonunda üretilen malın değeri 6 emek saati kadar olacaktır. Aynı işi niteliksiz bir işçi 8 saatte bitirdiğinde ise yine söz konusu malın değeri 6 emek saati üzerinden hesaplanacaktır. Bu örnekteki normal işiye göre hesaplanan 6 saat bu malın üretimi için gerekli sosyal 
emektir (Ertuğrul, 2014).

Daha önce Ricardo'da belirttiğimiz üzere dolaysız emek bir malın üretimi tekniğinde sadece harcanan emek zamanını içerirken, dolaylı emek bu malın üretiminde mal veya üretim araçlarının da kullanıldığ durumu ifade etmekteydi. Marx mal veya üretim araçlarının bulunduğu dolaylı emeği "değişen sermaye" ve "değişmeyen sermaye" olarak tanımlamıştır. Ona göre değişen sermaye ücretler ile satın alınan malların içerdiği emek zaman veya emeğin değeridir. Sermaye sahipleri tarafindan ücret olarak ödendiği için sermaye olarak nitelendirilmiştir (Günaydın, 2009). Değişmeyen sermaye ise dolaşan ve sabit sermaye olmak üzere tüm üretim araçlarının içerdiği emek miktarıdır. Sabit sermaye üretim araçlarından makine ve teçhizat gibi dayanıklı malları temsil ederken, dolaşan sermaye bir üretim döneminde kullanılan hammadde ve ara malları ifade etmektedir (Akyüz, 2009). Marx sabit sermayenin (c) makine veya teçhizatların bir malın üretiminde artı bir değer oluşturmadığını ancak değişen sermayenin $(v)$ yani emeğe ödenen ücretin daha fazla bir değer ürettiğini "artık değer" oluşturduğunu savunmuştur. Emeğe ödenen ücretin oluşturduğu bu artık değerin sermaye sahibinde bulunması Marx tarafından "emeğin sömürüsü" olarak tanımlanmıştır. Marx bu sömürü oranını $s / v$ olarak ifade etmiştir. Marx'a göre makine ve teçhizat gibi üretimde kullanılan sabit sermaye emeğin verimliliğini artırmaktadır. Artık oranındaki değişim ise iş günü veya zamanındaki değişmeler, emeğin verimliliğindeki değişimler ve emeğin karşıllı̆̆ geçimlilik ücretteki değişmeler bu artık değerin yani sömürü oranının değişmesine neden olmaktadır (Hunt, 2009). Marx'ın emek değer teorisinin temelini oluşturan artık değer kısaca emek sahibinin bir malın üretimi için harcadığı zaman ile bu çalışma karşılığında aldığ 1 ücret arasındaki farkı ifade etmektedir (Heilbroner, 2003).

\section{Fayda Değer Teorisi}

1870'li ylllarda İngiltere'de William Stanley Jevons (1835-1882), Avusturya'da Carl Menger (1840-1921) ve Lozan'da Leon Walras (1834-1910) fayda değer teorisinin gelişimine katkı sağlamışlardır. Jevons, değerin kaynağının fayda olduğunu düşünerek insanların ihtiyaçlarını en yüksek düzeyde karşılama isteği içinde olduklarını düşünmüştür. Bireylerin en düşük maliyetle veya çaba ile maksimum fayda sağladıklarını düşünürken bir malın tüketimi sonucunda sağladıkları toplam fayda ile en son tüketilen birimden sağlanan faydanın aynı olmadığını savunmuştur. Belirli bir noktadan sonra tüketiminin devam etmesinin toplam faydayı artırırken tüketilen son birimden sağlanan faydanın azaldığını düşünmüştür (Roncaglia, 2005).

Jevons bilimin matematiksel olması gerektiğini düşünerek ekonominin de bu nedenle matematiksel bir karakteri olması gerektiğini düşünmüş̧ür. Jevons bunu şu ifadelerle belirtmiştir: " rakamlarla uğraşan ekonomi biliminin, matematik analiz tekniği kullanması zorunludur." (Jevons, 1931). $\mathrm{Bu}$ nedenle Jevons rakamlarla iç içe olan ekonomi biliminde fayda değer teorisini, arz ve talebi, sermayeyi matematik ile açıllama çabası içinde olmuştur. Ona göre bir malın üretim maliyeti bu malın arzını belirlemektedir. Arzdaki değişmeler ise faydayı belirlerken, bu kanalla bir malın değişim değeri belirlenmektedir. Yani kısaca Jevons'a göre fayda bir malın değişim değerini belirlemektedir. Ona göre Ricardo ve Marx'ın düşündüğü gibi bir malın değerinin, o malı üretmek için harcanan emek zamanı miktarı belirlememektedir. Aksine bir malın faydalı olduğu için değerli olduğunu ve bu yüzden emek harcanarak üretildiğini düşünmüştür. Adam Smith'in meşhur "elmas-su paradoksu" elmasın faydası dikkate alınmadığı için ortaya çıkmıştır. Jevons elmasın tüketicilere fayda sağladığı için zaten değerli olduğunu ve insanların bu yüzden emek harcayarak onu çıkarttığını iddia etmiştir (Kazgan, 2006). 
Jevons faydanın bir malın tüketildiğinde mutluluk, haz veya acı hissi olduğunu yani bir malın fiziksel veya kimyasal özelliğinden kaynaklanmadığını, subjektif olduğunu düşünmüştür. Bir malın tüketiminden sağlanan toplam faydayı $U=f(x)$ şeklinde ifade etmiştir. Bu fonksiyona göre bir malın tüketim miktarının artması ile toplam faydanın artacă̆ını tespit etmiştir. Bir malın tüketiminin son biriminin toplam faydaya katkısı olan nihai (marjinal) fayda ise $M U=d u / d x$ olarak ifade edilmektedir (Ertuğrul, 2014). Bir malın tüketimi maliyetler açısından incelendiğinde bir $y$ ve $x$ malının olduğu varsayıldığında, tüketici $y$ malının bir kısmından vazgeçerek $x$ malı alıyorsa, bu iki mal arasinda marjinal faydaları ve fiyatları oranı karşılaştırılarak hangisinden ne kadar fazla tüketilebileceği veya hangisinden ne kadar vazgeçilebileceği belirlenebilir (Hunt, 2009).

Menger benzer ylllarda Jevons gibi değişim değerini fayda ile açıklamıştır. Ancak Jevons'tan farklı olarak o bir malın değişim değerini toplam fayda ve son biriminin tüketiminin toplam faydaya katkısı olan marjinal fayda ile açıklamıştır. Menger matematiksel ifade kullanmayarak, değerin ölçülmesinin tüketicilerin tercihlerine göre değişen subjektif bir olgu olduğunu savunmuştur (Bocutoğlu, 2012a). Menger malların fiyatları ile miktarları arasında negatif yönlü bir ilişki olduğunu kapitalist sistemde her üretim faktörünün karşılığını aldı̆̆ını ve sermaye sahipleri tarafindan sömürülen artık değerin oluşmadığını savunmuştur (Salerno, 2015). Ona göre bir malın değişim değeri arz ve talep unsurları tarafindan belirlenmektedir. Arz ve talebi belirleyen ise Jevons'mn bahsettiği gibi faydadır. Menger ülkenin zenginliğini iş bölümü ve uzmanlaşmada değil daha çok miktarda kaliteli mal üretmekte olduğunu düşünmüştür. Ona göre bir malın faydalı olabilmesi için o malı tüketme veya satın alma talebi bulunduran insan ihtiyacmnn varlı̆̆g, malın insanın ihtiyacını karşılayacak niteliğinin ve malın ihtiyacı karşılamaya uygun olarak kullanımının gerçekleştirilmesi gerekmektedir (Genç ve Çağlayan, 2017).

Walras faydanın değişim değerinin belirleyicisi olduğunu matematiksel denklemler ile açıllayarak, faydanın azalan bir fonksiyon olduğunu ifade etmiştir. Ona göre ekonomide bütün mal ve faktörlerin miktar ve fiyatları eşanlı bir dengededir. Walras'ın bu genel denge modelinde üreticiler karların maksimize etmek isterken, bireyler veya tüketiciler de faydalarını maksimize etme isteği ile davranarak belirli bir maliyet ve bütçe kısıtı altında denge noktasının belirlenmesini sağlamaktadır (M. K. Aydın ve Aydınlar, 2011). Walras'in analizinde bireyler tam bilgiye sahip, optimal tüketim yaparken toplumdan soyutlanmıştır. Üreticiler ise maliyet minimizasyonu yaparak karlarını en yükseğe çıkarma eğilimi içindedirler. Ona göre kültürel birliktelik, duygular, alışkanlıklar dikkate alınmayarak "fayda maksimizasyonu" yapılmaktadır. $\mathrm{Bu}$ nedenle Walras bireylerin kişisel çıkar peşinde koşmalarının matematiksel olarak çözümlenebileceğini düşünmüştür (Bilir, 2017).

Fayda değer teorisine bir diğer katkı da Alfred Marshall (1842-1924) tarafindan yapılmıştır. Marshall bir malın tüketiminden sağlanan faydanın azalan oranda artmasını "doygunluk yasası" olarak adlandırmıştır. Doygunluk yasasına göre bir malın tüketim miktarı artıkça toplam fayda artmakta, marjinal fayda ise azalmaktadır. Dolayısıyla malların değişim değeri marjinal faydalarına bağlıdır. Bu nedenle bir malın kit olması durumunda tüketilen en son birimin katkısı yüksek olacak ve söz konusu malın değeri de artacaktır. Malların marjinal faydaları oranı değişim oranlarını vermektedir (Akyüz, 2009).

$$
\frac{M U_{x}}{M U_{y}}=\frac{P_{x}}{P_{y}}
$$

Marshall malların marjinal faydaları oranının mallardan birinin veya ikisinin fiyatlarında bir değişme olmadığında ve birinde meydana gelen bir fiyat değişikliğ̈inin reel gelirde artışa neden olmadığında sabit 
olacağını varsaymıştır. Marshall "ceteris paribus" varsayımı yaparak fiyattaki değişmelerin bir malın talebi üzerindeki etkisini incelemiştir. Tüketicinin geliri, diğer malların fiyatları, harcamalar, zevk ve tercihler ve talep edilen malların miktarları sabitken (ceteris paribus), bir malın fiyatındaki değişme tüketicinin reel gelirini etkilemeyecektir. Tüketici talep edilen mal miktarları arasında bir değişme yapabilir.

\section{Karşılaştırma ve Değerlendirme}

Bu çalışmada ilk olarak değer kavramına değinildikten sonra değerin kaynağının ne olduğu araştırılmıştır. Bu kapsamda emek değer ve fayda değer teorileri incelenerek karşılaştırılmıştır. Değere ilişkin ilk düşünceler Aristo ve Aquinas'a kadar dayanmaktadır. Bir malın değişim değeri mallar arasındaki eşitlik ilkesine dayalı olarak değişime imkan tanıyan "adil fiyat" düşüncesi yerine A.Smith ile birlikte sermaye birikiminin olmadığ $\breve{g}_{1}$ toplumlarda emek zamanı ile nitelendirilmiştir. D. Ricardo ve K. Marx ise emeğin sermaye birikiminin ve özel mülkiyetin olduğu ve olmadığ dahi değerin tek belirleyicisi olduğunu ifade etmiştir. $\mathrm{Bu}$ iktisatçılar tarafindan geliştirilen ve "emek değer teorisi" olarak bilinen teoriye göre bir malın değeri o malın üretimi için harcanan emek zamanı miktarı ile belirlenmektedir. Dolayısıyla mallar arasındaki değişim oranını emek zamanı belirlemektedir.

Fayda değer teorisini benimseyen düşünürlerin görüşlerine göre ise bir malın değişim değerinin kaynağı yalnızca sağladığı faydadır. Elmasın değerinin yüksek olmasının onun faydasının yüksek olduğundan kaynaklandığını düşünmüşlerdir. Faydası yüksek olan malların üretimi için kullanılan emeğin ücretinin de yüksek olduğunu savunmuşladır. Fayda değer teorisini benimseyen düşünürler arasında faydanın ölçülebilir (kardinal) ve sıralanabilir (ordinal) olduğu hakkında çeşitli fikir ayrılıkları olmasına rağmen her iki görüşte de bir malın değişim değerinin fayda olduğu kabul edilmiştir. Toplam fayda ve marjinal fayda ayrımı yaparak toplam faydanın azalan oranda artığını savunmuşlardır. Ceteris paribus varsayımı yaparak bir malın fiyatındaki değişimin talebini nasıl etkilediğini tespit etmeye çalışmışlardır.

Emek değer teorisinde bir malın değişim değerini üretiminde kullanılan toplam emek zamanı miktarı belirlerken fayda değer teorisinde ise bir malın değişim değerini toplam fayda değil, malın son biriminin toplam faydaya yaptığı katkıyı ifade eden marjinal fayda belirlemektedir. Emek değer teorisinde malların değeri objektif bir ölçüt olan emek miktarı ile mutlak olarak ölçülürken, fayda değer teorisinde marjinal fayda kavramı subjektif bir kavram olduğu için bir malın değerinin kaynağ mutlak bir ölçme imkanı bulunamamaktadır. Dolayısıyla fayda değer teorisinde malların fiyatları oranlarını marjinal faydaları oranına eşitliği mutlak bir değer ölçümünü sağlamamaktadır.

Günümüzde bir malın değerinin yalnızca onun üretimi için kullanılan emek zamanı tarafindan belirlenmesi mümkün değildir. Nitekim emeğin yanında üretimde kullanılan diğer faktörler de yer almaktadır. Ayrıca değerin kaynağının fayda olduğu ve bir malın faydalı olduğu için değerli olduğunu kabul etmek mutlak bir doğru değildir. "Ceteris paribus" varsayımı altında fiyattaki değişmelerin bir maldan tüketilen miktarın tespit edilmesini her ne kadar kolaylaştırsa da ekonomide gerçekte bir malın talep edilen miktarını birçok değişken aynı anda etkileyebilmektedir. Bu bağlamda "ceteris paribus" varsayımı birçok etkinin aynı anda sonucunu analiz etmek için, etkilerin birbirinden bağımsız sonuçlarının bilinmesini gerekli kılar. Bu nedenle bu varsayım değişkenlerin birbirinden bağımsız etkilerinin sonucunu tespit etme ihtiyac1 amaciyla hareket etmektedir.

Marjinal fayda teorisine göre $\frac{M U_{x}}{M U_{y}}=\frac{P_{x}}{P_{y}}$ olduğu durumda $x$ ve $y$ malının değişim oranları belirlenmektedir. Tüketicinin ras- 
yonel davrandığı varsayımı altında $x$ ve y mallarının ikisinin de aynı özelliklere sahip cep telefonu olduğunu varsayalım. (Örneğin ikisinin de kamerası, hafızası vs. tüm özellikleri aynı) Ancak telefonlardan $x$ 'in piyasa satış fiyatının daha pahalı ve daha önceden piyasada tanınmış bir marka olduğunu varsayalım. Telefonlardan y'nin ise piyasaya yeni girmiş, satış fiyatının daha düşük bir marka olduğunu ve her iki malın da bir biriminin üretim maliyetinin ayn olduğunu varsayalım. Tüketiciler rasyonel birey ise aynı özelliklere sahip ve daha düşük fiyatlı olan $x$ malını tercih edeceklerdir. y telefonunun sağladığı fayda, ona sahip olunduğunda alınan mutluluk ve haz daha fazla olduğunda ise tüketiciler $y$ malını tercih edeceklerdir. Böyle bir durumda tüketiciler rasyonel davranmayarak, aynı özelliklere sahip daha ucuza satın alabilecekleri bir malı daha pahalıya satın alacaklardır. Tüketicinin $y$ malını tercih etmesi bu malın faydasının yüksek olduğundan değil, bu malı talep eden tüketicilerin zevk ve tercihlerinin, gelirlerinin ve o mala sahip olma isteğinin etkisi olabilir. Bir birinin tamamen ikamesi olan bu mallarda dahi değerin birçok nedenle farklı olabilmektedir. $x$ ve $y$ malının üretimi açısında değerleri incelendiğinde bu malların üretiminde kullanılan emek miktarı aynı olmaya bilir, bu malların üretim maliyetleri farklı olabilir, $x$ malı daha ucuz emek veya nitelikli emekle üretildiği için piyasa fiyatı daha ucuz olabilir. $y$ malı üretiminde emeğe ödenen ücret daha fazla olabilir ya da snop etkisi ile piyasa fiyatı daha yüksek olabilir. $\mathrm{Bu}$ mallar sağladıkları fayda açısından incelendiğinde fiyatları oranının faydaları oranına eşit olmayacağı düşünülmektedir. Yani aynı özelliklere sahip telefonların tüketicilerin ihtiyaçlarını karşılamada eşit olduğu düşünüldüğünde her birey için aynı faydayı sağlamayacağı, faydanın kişiden kişiye değişmesi nedeniyle tespit edilemeyeceği düşünülmektedir.

Değerin oluşmasında arz ve talebin de etkili olduğu düşünülmektedir. Ancak arzı ve talebi belirleyen unsurlarm neler olduğunun mutlak olarak tespit edilmesi mümkün olamayacağı kanısına varılmıştır. Çünkü arz ve talebi belirleyen çok sayıda değişken vardır. Bu nedenle bir malın değerini, o malın sağladığı fayda, üretiminde ortaya çıkan maliyetler, tüketicilerin zevk ve tercihleri, o malın kitlığ piyasada bulunan rakip mallarm fiyatı, arz ve talebi, o mala olan ihtiyacın şiddeti, döviz kurundaki değişikliklerin rakip malların piyasaya girişinde oluşturduğu değişim, yaşanan salgın, krizler ve siyasi gerginlikler gibi bir çok etken belirlemektedir. Bu nedenle değerin sadece fayda ya da emek tarafindan belirlenmesi mümkün olmadığı düşünülmektedir.

\section{Kaynakça}

Adaçay, F. R. (2017). Modern İktisadi düşüncenin doğuşu: Merkantilizm ve fizyokrasi. In M. B. Erdem ve H. İslatince (Ed.), İktisadi düşünceler tarihi. Eskişehir: Anadolu Üniversitesi Yayınları.

Akyüz, Y. (1980). Sermaye bölüşüm büyüme (Ankara Üniversitesi Siyasal Bilgiler Fakültesi Yayınları No. 441). Ankara: Ankara Üniversitesi.

Akyüz, Y. (2009). Sermaye bölüşüm büyüme. Ankara: Efil Yaymevi.

Aydın, I., ve Yılmaz, K. (2014). Eğitim yönetimi, denetimi ve politikası yazıları. Ankara: Ayrıntı Basım Yayın ve Matbaacılık Pegem Akademi.

Aydın, M. K., ve Aydınlar, K. (2011). Emek-değer teorisinden fayda-değer teorisine. Bilgi Sosyal Bilimler Dergisi, 13, 1-12. https://dergipark.org .tr/en/pub/bilgisosyal/issue/29132/311613.

Bilir, H. (2017). Léon walras: Neoklasik İktisadın fiziko-matematiksel bir bilim olarak İnşası. Uluslararası Yönetim Íktisat ve İşletme Dergisi, 13(5), 131-142. doi:10.17130/ijmeb.2017ICMEB1735441

Bocutoğlu, E. (2012a). İktisadi düşünceler tarihi. Trabzon: Murathan Yayınevi.

Bocutoğlu, E. (2012b). İktisat teorisinde emeğin Öyküsü: Değerin kaynağı olan emekten marjinal faydanın türevi olan emeğe yolculuk. Hakİs Uluslararası Emek ve Toplum Dergisi, 1(1), 127-150. https://dergipark.org.tr/en/pub/ hakisderg/issue/7575/99445.

Çöpoğlu, M., ve Kuran, M. (2019). İbn haldun'da Çalışma hayatına yönelik Üç temel kavramın İncelenmesi:Çalışma, emek değer ve İş bölümü. Kocaeli Üniversitesi Sosyal Bilimler Dergisi, 38 , 131-142. doi:10.35343/kosbed.651296

Demir, D. (2016). Değer kavramı ve lo- 
jistik hizmetlerinin müşteride yarattı̆̆ değer. Journal of Current Researches on Business and Economics, 6(2), 1-28. https://www.researchgate.net/publication/ 328531819_Deger_Kavrami_ve_Lojistik _Hizmetlerinin_Musteride_Yarattigi_Deger.

Desai, M. (2009). Marksist Iktisat teorisi (N. Satlıgan, Çev.). Ankara: Efil Yayınevi.

DeSarbo, W. S., Jedidi, K., ve Sinha, I. (2001). Customer value analysis in a heterogeneous market. Strategic Management Journal, 22(9), 845-857. doi:10.1002/smj.191

Doğruyol, A., ve Aydınlar, K. (2015). Emek üretkenliği ve ücret teorisi. Çukurova Universitesi Sosyal Bilimler Enstitüsü Dergisi, 24(2), 263-278. https://dergipark.org.tr/en/pub/ cusosbil/issue/32044/354257.

Erdem, M. B. (2017). İktisadi düşünceler tarihine giriş. In M. B. Erdem ve H. İslatince (Ed.), İktisadi düşünceler tarihi. Eskişehir: Anadolu Üniversitesi Yaymları.

Ertuğrul, A. (2014). Ekonomik teori ve analizin tarihi. Ankara: Efil Yaymevi.

Genç, S. Y., ve Çağlayan, T. (2017). İktisadi düşüncede değerin kaynağı sorunsalı. Calisma ve Toplum, 53(2). http://www.calismatoplum . org/sayi53/genc.pdf.

Gözen, M. (2019). Değer ve değerleme hakkında kavramsal ve kuramsal bir çalışma. Selçuk Üniversitesi Sosyal Bilimler Meslek Yüksekokulu Dergisi, 22(2), 374-382. doi:10.29249/selcuksbmyd.481913

Günaydın, G. (2009). Smith, ricardo ve marx iktisadında tarım (emek, değer ve rant teorisi yaklaşımları bağlamında). Mülkiye Dergisi, 33(262), 345-362. https://dergipark.org.tr/ en/pub/mulkiye/issue/262/658.

Güngör, E. (1993). Değerler psikolojisi: Ahlak psikolojisi, ahlaki değerler ve ahlaki gelişme. Hollanda: Hollanda Türk Akademisyenler Birliği Vakfı Yayınları.

Haldun, I. (2018). Mukaddime (S. Uludă̆, Çev.). İstanbul: Dergah Yayınları.

Heilbroner, R. L. (2003). Ikktisat düşünürleri (A. Tartanoğlu, Çev.). Ankara: Dost Kitabevi.

Hunt, E. K. (2009). İktisadi düşünce tarihi (M. Günay, Çev.). Ankara: Dost Kitabevi.

İşler, I. (2018). Kamu kaynaklarının etkin kullanımında fayda-maliyet analizinin uygulanmasina bir örnek: Denizli havalimanı projesi (Doktora Tezi). Denizli: Pamukkale Üniversitesi Sosyal Bilimler Enstitüsü. https://tez.yok .gov.tr/UlusalTezMerkezi/TezGoster?key= MzP7PYssFqdb3WIjlroAkVsesxHUhdQsqf3aHoZPpsum8njgk -BKgerQdwtZlCah.

Jevons, W. S. (1931). The theory of political economy (W. S. Jevons, Çev.). London: Macmillan and Company.

Kauder, E. (2015). Genesis of marginal utility theory. Princeton University Press.

Kazgan, G. (2006). İktisadi düşünce veya politik Iktisadın evrimi. Istanbul: Remzi Kitapevi.
Koç, Y. (2014). Marksist emek değer kuramı ve emperyalist dönemde kapitalist sömürü. Bilim ve Ütopya Dergisi, 239, 113. http://www.yildirimkoc.com.tr/usrfile/ 1401701915b.pdf.

Küçükkalay, A. M. (2017). Adil fiyat. İstanbul: Ötüken Yayıncılık.

Küçükkalay, A. M. (2019). Iktisadi düşünce tarihi. İstanbul: Beta Yayınları.

Marx, K. (2011). Kapital cilt $i$ (M. Selik ve N. Satılgan, Çev.). İstanbul: Yordam Kitap Basın ve Yayın.

Niehans, J. (1994). A history of economic theory: Classic contributions 1720-1980. Baltimore: Johns Hopkins University Press.

Ricardo, D. (1891). Principles of political economy and taxation. G. Bell and sons.

Roncaglia, A. (2005). The wealth of ideas. Cambridge: Cambridge University.

Salerno, J. T. (2015). Carl menger: Avusturya okulu'nun kuruluşu (U. Çetin, Çev.). In R. G. Holcombe (Ed.), The great austrian economists. Creative Media Partners.

Savaş, F. V. (2000). İtisadın tarihi. Ankara: Siyasal Kitapevi.

Selik, M. (1980). Marksist değer teorisi (Ankara Üniversitesi Siyasal Bilgiler Fakültesi Yayınları No. 484). Ankara: Ankara Üniversitesi.

Sewall, H. R. (1901). The theory of value before adam smith.

Sraffa, P. (Ed.). (1951). The works and correspondence of david ricardo (Vol. 1). Cambridge: Cambridge University Press. 


\title{
Comparative Analysis of Labor Theory of Value and Utility Theory of Value
}

\author{
TuĞBA KOYUnCU (iD ${ }^{1}$ \\ Received:21.05.2020; Revised:29.05.2020; Accepted:01.06.2020
}

\begin{abstract}
The issue of value and what the source of value is has been the subject of research for economists and thinkers for a long time. Adam Smith, David Ricardo and Karl Marx did not consider the use value of a good. By considering the exchange value of a good, they argued that the exchange value of that good was determined by the amount of labor time spent in its production. Although these economists approached the theory of labor value with different perspectives, they reached a common consensus that the source of value is labor. Another approach contributed to the theory of value is the theory of utility value led by W. Stanley Jevons, Leon Walras, Carl Menger and Alfred Marshall. In this study, theory of labor value and theory of utility value are compared, and their validity today is discussed. We think we cannot reach to the conclusion that the value affected by many variables in the economic system cannot be determined by only labor or utility in such a complex structure of today. It is also concluded that there are many other variables that affect the value of good other than labor and benefit.
\end{abstract}

JEL codes: B10, B12, B13

Keywords: Value Consept, Labor Value Theory, Utility Value Theory

\section{Extended Summary}

The question of what the source of value is for many years has been a topic discussed by many economist and thinkers. It was discussed by many economists and thinkers on which criteria the exchange between goods will be determined and how the distribution will be distributes among factors of production such as capital and labor. Therefore, many theories have been derived about what determines the value of a good. In this study, "labor value theory" and "utility value theory" were examined comparatively to determine what determined the value of a good.

\footnotetext{
${ }^{1}$ Department of Economics Doctoral Program, Institute of Social Scienses, Eskisehir Osmangazi University, Turkey. (e-mail: tugbakoyuncu9106@gmail.com)
}

The study of the value problematic dates back to Plato and Aristotle which of the Medieval thinkers. Aristotle (384-322 B.C), examining what the source of value is, explained the value by considering a few basic elements. He thought that the value of a good determines the value of the good in addition to the benefit it provides to the owner of that good. Aristotle thought that the demand for a good would change depending on the order of use. He also stated that the scarcity of a good was effective in determining the value of that good.

Usage value and exchange value of good are different concepts. The value of use refers to the benefit that occurs during the consumption of a good. The exchange 
value is the value that provides the swap between goods. The theories developed on value generally result from the difference between exchange value and usage value. Economists such as Adam Smith, David Ricardo and Karl Marx did not take into account the value of use a good. They mostly took into account the exchange value of a good. They thought that the exchange value of a good determines the amount of labor time spent in its production. Although these economists approached the theory of labor value with different perspectives, they reached a common consensus that the source of value is labor time.

Adam Smith divided the time into two. He explained what is the determined of the value of good when there is capital accumulation and private property and when there is no capital accumulation and private property. According to this model, times in the absence of capital accumulation and private property the amount of labor time used for the production of a good determines the value of that good. In times of capital accumulation, it is thought that the value of a good is determined by the labor factor as well as production factors such as capital and land. Based on this theory, David Ricardo and Karl Marx have adopted that value is determined by labor at all times. In other words, they thought that the determinant of the value of a good is the amount of labor time spent of fpr the production of that good at all times, with and without capital accumulation and private property.

According to the utilitarian approaches, the use value of a good, that is its utility, determines the exchange value of that good. William Stanley Jevons, Carl Menger and Leon Walras is among economists who contributed to the development of utility theory of value. According to W.S. Jevons, benefit determines the exchange value of a good. According to him, as D. Ricardo and C. Marx thought, the value of a good does not determine the amount of labor time spent producing it. On the contrary, he thought that a good was valuable because it was beneficial and therefore it was produced by effort. In similar years, Menger explained the value of change like Jevons with benefit. However, unlike Jevons, he explained the exchange value of a good with total benefit and marginal benefit which contributes to the total benefit of the consumption of the final unit. Menger argued that the measurement of value is a subjective phenomenon that varies according to consumers preferences by not using mathematical expressions. So what really determines the value of a good? Does the amount of labor time used to produce a good value determine? Or does it determine the amount of benefit that a good contains? In this study, the answer to the question of what determines the value of a good is sought. For this reason, by comparing the labor value theory and benefit value theory, their current validity is discussed. Therefore, the main purpose of the study is to analyze the labor value theory comparatively and to determine what determines the value of a good.

In this study, the concept of value was first mentioned and then the source of the value of a good was investigated. In this context, labor value theory and benefit value theory are analyzed and compared. Supply and demand are also thought to be effective in creating value. However, it was concluded that it would not be possible to determine what the factors determining supply and demand are absolutely. Because the are many variables that determine supply and demand. Therefore, the value of a good determines bt many factor such as the benefit it provides the costs associated with its production, the tastes and preferences of consumers, the shortage or abundance of that good, the price of competing goods, the severity of the need fort that good, changes in the exchange rate, outbreaks, crises and political tensions. For this reason, it is thought that value cannot be determined only by benefit or labor. 
As a result it is thought that the value affected by many variables in the economic system cannot be concluded from such a complex structure that it can only be determined by labor or just benefit. It is also considered that there are many variables that affect the value of good other than labor and benefit. 